\title{
Successful Treatment with a Weekly Injection of Teriparatide for the Nonunion of a Distal Humerus Fracture
}

\author{
Hiroshi Yonezu, Hiroshi Mikami, Koichi Oba, Katsutoshi Miyatake, \\ Michihiro Takai, Akihiro Nitta \\ Department of Orthopedics, Yoshinogawa Medical Center, Yoshinogawa, Tokushima, Japan \\ Email: hyonezu@kj9.so-net.ne.jp
}

How to cite this paper: Yonezu, H., Mikami, H., Oba, K., Miyatake, K., Takai, M. and Nitta, A. (2017) Successful Treatment with a Weekly Injection of Teriparatide for the Nonunion of a Distal Humerus Fracture. Open Journal of Orthopedics, 7, 173-179. https://doi.org/10.4236/ojo.2017.77019

Received: March 22, 2017

Accepted: July 1, 2017

Published: July 4, 2017

Copyright $\odot 2017$ by authors and Scientific Research Publishing Inc. This work is licensed under the Creative Commons Attribution International License (CC BY 4.0).

http://creativecommons.org/licenses/by/4.0/ cc) (i) Open Access

\begin{abstract}
A distal humerus fracture nonunion is one of the complications with which we should be vigilant. It requires an open reduction and rigid internal fixation. However, treatment with an operative procedure is difficult because the small bones involved in distal humerus fracture nonunion or if osteoporosis is present. And an improvement in the function of the elbow joint is not satisfied because of a postoperative elbow joint contracture. Furthermore, the risk of anesthesia to elderly patients restricts the use of an operation for treatment. A weekly injection of teriparatide has the ability to stimulate bone formation. We present a case of an 87-year-old woman treated with a weekly injection of teriparatide for the nonunion of a distal humerus fracture.
\end{abstract}

Keywords

Distal Humerus Fracture, Nonunion, Teriparatide

\section{Introduction}

A distal humerus fracture in an adult requires osteosynthesis, but it can easily result in nonunion and an elbow joint contracture, which results in the inability to have a strong inner fixation in the elderly and rheumatoid arthritis patients [1].

It is common to treat a nonunion after a bone fracture with an inner fixation that uses a bone graft with the operation [2]. However, an operation may not be performed due to the risks created by general anesthesia and an invasive operation in a patient with advanced age or past illnesses.

Teriparatide has the ability to stimulate bone formation and thus has potent 
anabolic effects on bone [3]. Several reports suggest that teriparatide is effective for healing fractures or nonunion [4] [5]. However, there are few reports on the effect of a weekly injection of teriparatide.

We present our experience with a case of nonunion of a distal humerus fracture treated with a weekly injection of teriparatide.

\section{Case Presentation}

An 87-year-old woman was injured by a fall. She consulted a local doctor and was diagnosed with a distal humerus fracture, for which she underwent plaster cast fixation treatment. However, she was introduced to our hospital because bone union had not occurred, even after three months of therapy. On plain radiographs or computed tomography (CT) images, there was no transposition of the fractured bone, but instead, a bone fracture gap was seen (Figure 1). The border of the fractured bone was stiffened; however, a callus formation was no confirmed. There was not clinical or laboratory evidence of infection. Therefore, we made the diagnosis of nonunion.

The bone density was $71 \%$ and $66 \%$ of the young adult mean (YAM) at the lumbar vertebral and proximal femoral levels, respectively. Tartrate-resistant acid phosphatase 5b (TRACP5b) was high, but other data were normal (Table $1)$.

She was an elderly patient, and, thus was considered a high-risk patient for an operation with general anesthesia. She did not agree to the operation. Therefore, we selected conservative treatment with once -weekly injections of teriparatide

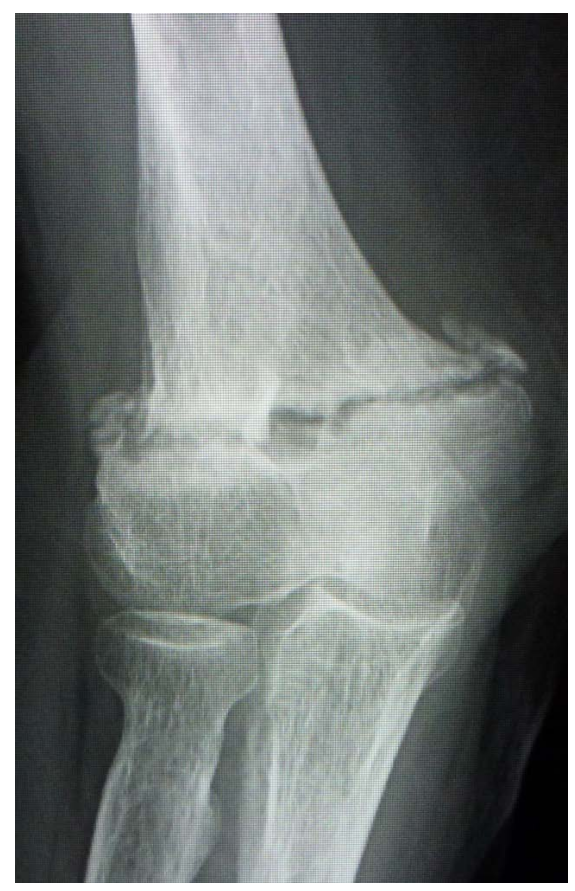

(a)

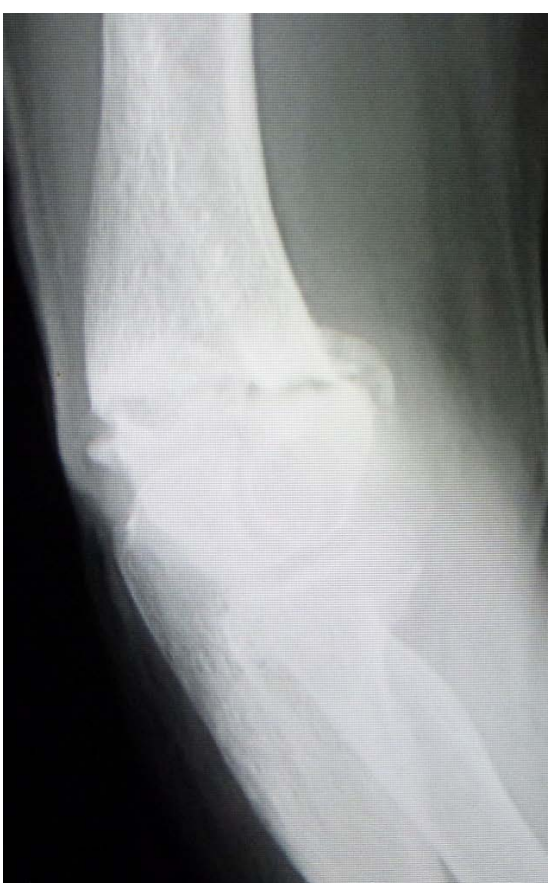

(b)

Figure 1. Plain radiographs (a) and (b) showed the nonunion of the distal humerus fracture at the first visit to our hospital. 
Table 1. Laboratory data.

\begin{tabular}{cccc}
\hline Parameter & Data & Unit & standard value \\
\hline WBC & 5.49 & $\times 1000 / \mu \mathrm{L}$ & $4.00-9.00$ \\
$\mathrm{RBC}$ & 4.44 & $\times 1,000,000 / \mu \mathrm{L}$ & $3.76-5.00$ \\
$\mathrm{Hb}$ & 12.4 & $\mathrm{~g} / \mathrm{dL}$ & $12.0-16.0$ \\
$\mathrm{PLT}$ & 209 & $\times 1000 / \mu \mathrm{L}$ & $150-350$ \\
$\mathrm{Na}$ & 142 & $\mathrm{~m} \mathrm{~mol} / \mathrm{L}$ & $135-146$ \\
$\mathrm{~K}$ & 4.0 & $\mathrm{~m} \mathrm{~mol} / \mathrm{L}$ & $3.5-4.8$ \\
$\mathrm{CL}$ & 107 & $\mathrm{~m} \mathrm{~mol} / \mathrm{L}$ & $98-100$ \\
$\mathrm{Ca}$ & 9.5 & $\mathrm{mg} / \mathrm{dl}$ & $8.5-10.2$ \\
$\mathrm{P}$ & 3.23 & $\mathrm{mg} / \mathrm{dl}$ & $2.5-4.5$ \\
$\mathrm{BAP}$ & 20.8 & $\mu \mathrm{g} / \mathrm{L}$ & $3.8-22.6$ \\
TRACP-5B & 846 & $\mathrm{mU} / \mathrm{dL}$ & $120-420$ \\
\hline
\end{tabular}

BAP: bone specific alkaline phosphatase; TRACP-5b: tartrate-resistant acid phosphatase $5 \mathrm{~b}$.

(56.5 $\mu \mathrm{g} /$ week) used in conjunction with plaster splint fixation for three months. After 6 months of teriparatide treatment, CT images showed that the gap of the fracture decreased and the bone gradually healed. After teriparatide treatment for the 12 months, bony union was evident and teriparatide was discontinued. There were no teriparatide-related side effects during or after the treatment. Three months after discontinuation of the teriparatide, complete union was obtained as seen on plain radiographs and CT images (Figure 2 and Figure 3 ).

After teriparatide treatment for the 12 months, the range of motion at the elbow joint was good (range: $-10-130$ ), and she had no problems with activities of daily living (Figure 4).

\section{Discussion}

It is said that a distal humerus fracture accounts for $0.5 \%$ to $2 \%$ of all fractures. A fracture to the distal humerus occurs by high-energy damage in younger patients, and that by low-energy damage in the elderly is common. As age advances in an elderly person with osteoporosis, it is said that the incidence of distal humerus fractures increases. Anatomically, the distal humeral region is where the difficulty with fixation occurs. In the elderly population with osteoporosis, a strong fixation is very difficult [6].

It regards to bone fracture around the elbow, a distal humerus fracture nonunion is one of the complications with which we should be vigilant. The nonunion of the distal humerus fracture is usually associated with instability, abnormal motion, reduction of elbow motion, and a functional loss. They require an open reduction and rigid internal fixation; however, treatment with an operative procedure is difficult because of the small bones involved in distal humerus fracture nonunion or if osteoporosis is present. Helfet et al. treated 52 cases of distal humerus fracture nonunion. Bony union occurred in 51 cases with an av- 


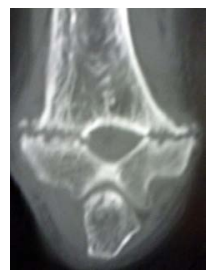

(a)

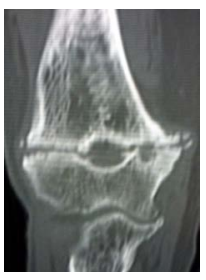

(b)

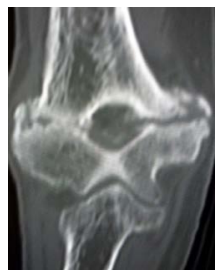

(c)

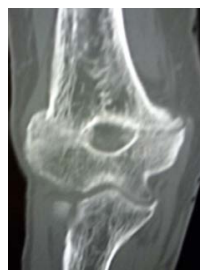

(d)

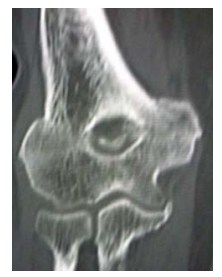

(e)

Figure 2. CT scan (a) showed the nonunion of the distal humerus fracture. After teriparatide treatment for 6 months; CT scan (b) showed that the gap of fracture department became small; the healing of bone fracture was gradually provided; after treatment for 9 months) (c). After teriparatide treatment for the 12 months (d); bony union was evident; at the 3 months after discontinuation of teriparatide; complete union was obtained (e).

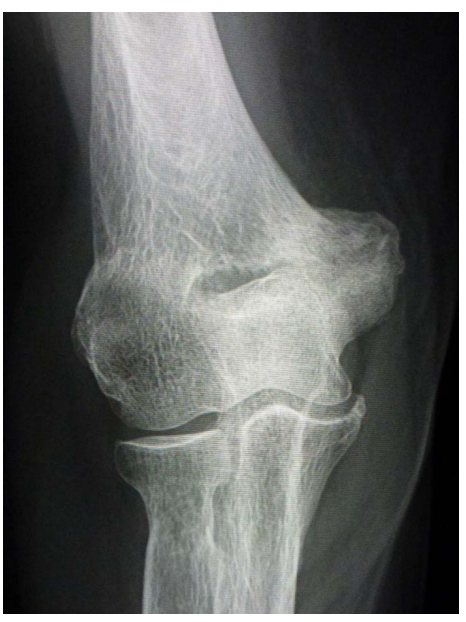

(a)

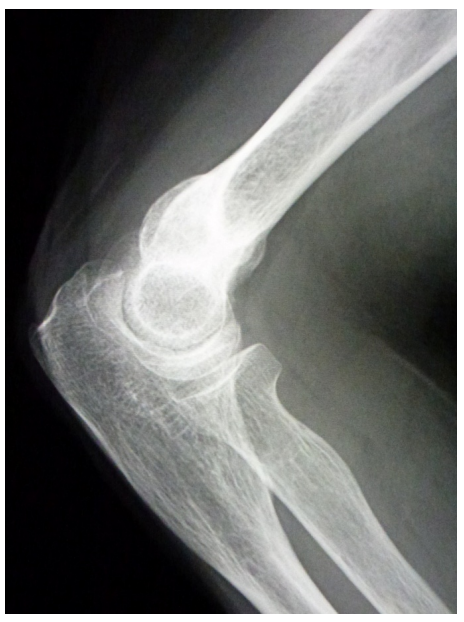

(b)

Figure 3. Plain radiographs (a) and (b) showed the complete union of the distal humerus fracture at the 3 months after discontinuation of teriparatide.

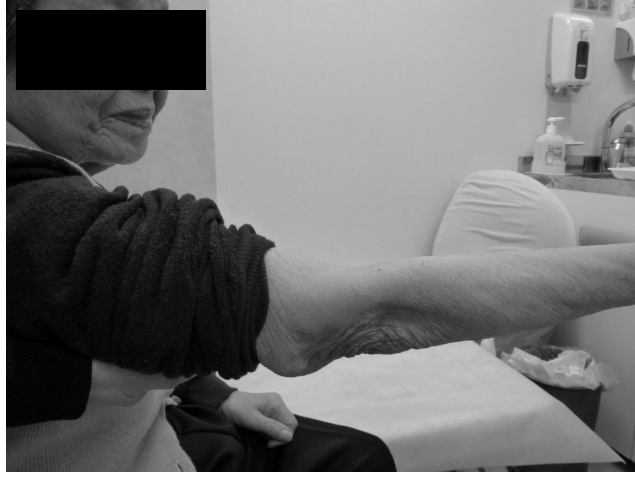

(a)

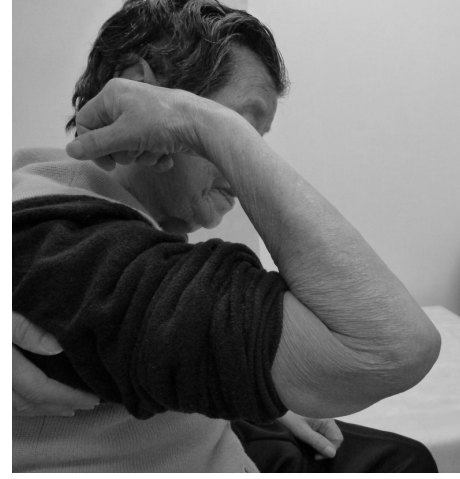

(b)

Figure 4. After teriparatide treatment for the 12 months. The range of motion ((a) extension; (b) flexion) is good.

erage time to union of 6 months. The range of motion of the elbow increased from an average of 71 degrees preoperatively to 94 degrees postoperatively [7] [8]. Allende et al. treated 24 cases of the nonunion of the distal humerus fracture, and bony union occurred in all cases with an average time to union of 5 
months. The average range of motion of the elbow during the last examination was 98 degrees. Flexion was an average of 110 degrees and extension averaged -17 degrees [9]. The results of the bone union acquisition with the operative treatment improve by the progress of implants in late years so that their reports include it. However, an improvement in the function of the elbow joint is not satisfied because of a postoperative elbow joint contracture. Furthermore, the risk of anesthesia to elderly patients restricts the use of an operation for treatment.

Teriparatide has potent anabolic effects on bone because of its ability to stimulate bone formation. Several reports suggest that the daily injection of teriparatide is effective for fracture or nonunion healing [10] [11]. Lin et al. report on its use for nonunion in a femoral fracture mouse model. They were able to significantly decrease the bone fracture gap by giving daily injections of teriparatide [12]. In a clinical report, Chintamaneni et al. report on its use for the nonunion of sternal fracture. They use a daily injection of teriparatide to treat sternal fracture nonunion. Callus formation occurred in 3 months and bone union was complete 9 months later [13]. In addition, Lee et al. report its use in 3 cases of femoral fracture nonunion. Bone union occurred 3 to 9 months later by giving a daily injection of teriparatide [14].

It is reported that a weekly injection of teriparatide has the ability to stimulate bone formation, but there are few reports on its ability to stimulate bone union [15] [16]. We gave a weekly injection of teriparatide for the nonunion of a distal humerus fracture that occurred in an elderly patient. The narrowing of the bone fracture gap occurred after 6 months of starting treatment and bone union occurred at 12 months. In addition, there were a few restrictions to the elbow joint excursion, but there was no trouble that affected the everyday life. This is the first report of the successful use of once weekly teriparatide to treat nonunion of a distal humerus fracture.

Based on our experience, we conclude that, in cases where an operation is difficult due to the use of general anesthesia in the elderly or those with past illness, a weekly injection of teriparatide treatment is effective for the nonunion of a distal humerus fracture.

Future well-designed studies are needed to verify the efficacy of this approach.

\section{Consent}

The authors obtained consent for the publication from the patient.

\section{Competing Interests}

The authors declare that there is no conflict of interest regarding the publication of this paper.

\section{References}

[1] Aitken, G.K. and Rorabeck, C.H. (1986) Distal Humeral Fractures in the Adult. Clinical Orthopaedics and Related Research, 207, 191-197. https://doi.org/10.1097/00003086-198606000-00034

[2] Ring, D., Gulotta, L. and Jupiter, J.B. (2003) Unstable Nonunions of the Distal Part 
of the Humerus. The Journal of Bone and Joint Surgery, 85, 1040-1046. https://doi.org/10.2106/00004623-200306000-00008

[3] Tashjian, A.H. and Gagel, R.F. (2006) Teriparatide [Human PTH (1-34)]: 2.5 Years of Experience on the Use and Safety of the Drug for the Treatment of Osteoporosis. Journal of Bone and Mineral Research, 21, 354-365. https://doi.org/10.1359/JBMR.051023

[4] Aspenberg, P., Genant, H.K., Johansson, T., Nino, A.J., See, K., Krohn, K., Garcia-Hernandez, P.A., Recknor, C.P., Einhorn, T.A., Dalsky, G.P., Mitlak, B.H., Fierlinger, A. and Lakshmanan, M.C. (2010) Teriparatide for Acceleration of Fracture Repair in Humans: A Prospective Randomized, Double-Blind Study of 102 Postmenopausal Women with Distal Radial Fractures. Journal of Bone and Mineral Research, 25, 404-414. https://doi.org/10.1359/jbmr.090731

[5] Manabe, T., Mori, S., Mashiba, T., Kaji, Y., Iwata, K., Komatsubara, S., Seki, A., Sun, Y.X. and Yamamoto, T. (2007) Human Parathyroid Hormone (1-34) Accelerates Natural Fracture Healing Process in the Femoral Osteotomy Model of Cynomolgus Monkeys. Bone, 40, 1475-1482. https://doi.org/10.1016/j.bone.2007.01.015

[6] Ilyas, A.M. and Jupiter, J.B. (2008) Treatment of Distal Humerus Fractures. Acta Chirurgiae Orthopaedicae et Traumatologiae Cechosl, 75, 6-15.

[7] Helfet, D.L., Kloen, P, Anand, N. and Rosen, H.S. (2003) Open Reduction and Internal Fixation of Delayed Unions and Nonunions of Fractures of the Distal Part of the Humerus. The Journal of Bone and Joint Surgery American Volume, 85, 33-40. https://doi.org/10.2106/00004623-200301000-00006

[8] Helfet, D.L., Kloen, P., Anand, N. and Rosen, H.S. (2004) ORIF of Delayed Unions and Nonunions of Distal Humeral Fractures. The Journal of Bone and Joint Surgery American Volume, 86, 18-29. https://doi.org/10.2106/00004623-200400001-00004

[9] Allende, C. and Allende, B.T. (2009) Post-Traumatic Distal Humerus Non-Union: Open Reduction and Internal Fixation: Long-Term Results. International Orthopaedics, 33, 1289-1294. https://doi.org/10.1007/s00264-008-0650-8

[10] Peichl, P., Holzer, L.A., Maier, R. and Holzer, G. (2011) Parathyroid Hormone 1-84 Accelerates Fracture-Healing in Pubic Bones of Elderly Osteoporotic Women. The Journal of Bone and Joint Surgery American Volume, 93, 1583-1587. https://doi.org/10.2106/JBJS.J.01379

[11] Resmini, G. and Iolascon, G. (2007) 79-Year-Old Post-Menoppausal Woman with Humerus Fracture during Teriparatide Treatment. Aging Clinical and Experimental Research, 19, 30-31.

[12] Lin, E.A., Liu, C.J., Monroy, A., Khurana, S. and Egol, K.A. (2012) Prevention of Atrophic Nonunion by the Systemic Administration of Parathyroid Hormone (PTH 1-34) in an Experimental Animal Model. Journal of Orthopaedic Trauma, 26, 719-723. https://doi.org/10.1097/BOT.0b013e31826f5b9e

[13] Chintamaneni, S., Finzel, K. and Gruber, B.L. (2010) Successful Treatment of Sternal Fracture Nonunion with Teriparatide. Osteoporosis International, 21, 10591063. https://doi.org/10.1007/s00198-009-1061-4

[14] Lee, Y.K., Ha, Y.C. and Koo, K.H. (2012) Teriparatide, A Nonsurgical Solution for Femoral Nonunion? A Report of Three Cases. Osteoporosis International, 23, 2897-2900. https://doi.org/10.1007/s00198-012-2172-x

[15] Fujita, T., Inoue, T., Morii, H., Morita, R., Norimatsu, H., Orimo, H., Takahashi, H.E., Yamamoto, K. and Fukunaga, M. (1999) Effect of an Intermittent Weekly Dose of Human Parathyroid Hormone (1-34) on Osteoporosis: A Randomized Double-Masked Prospective Study Using Three Dose Levels. Osteoporosis International, 9, 296-306. https://doi.org/10.1007/s001980050151 
[16] Miki, T., Nakatsuka, K., Naka, H., Masaki, H., Imanishi, Y., Ito, M., Inaba, M., Morii, H. and Nishizawa, Y. (2004) Effect and Safety of Intermittent Weekly Administration of Human Parathyroid Hormone 1-34 in Patients with Primary Osteoporosis Evaluated by Histomorphometry and Microstructural Analysis of Iliac Trabecular Bone before and after 1 Year of Treatment. Journal of Bone and Mineral Metabolism, 22, 569-576. https://doi.org/10.1007/s00774-004-0525-Z

Submit or recommend next manuscript to SCIRP and we will provide best service for you:

Accepting pre-submission inquiries through Email, Facebook, LinkedIn, Twitter, etc. A wide selection of journals (inclusive of 9 subjects, more than 200 journals)

Providing 24-hour high-quality service

User-friendly online submission system

Fair and swift peer-review system

Efficient typesetting and proofreading procedure

Display of the result of downloads and visits, as well as the number of cited articles

Maximum dissemination of your research work

Submit your manuscript at: http://papersubmission.scirp.org/

Or contact ojo@scirp.org 